\title{
Sociology of nutrition: theory and practice
}

\author{
Larisa Zhuravleva, Elena Zarubina, Aleksey Ruchkin*, Natalya Simachkova, and Irina \\ Chupina
}

Ural State Agrarian University, 620075 ul. Karl Liebknecht, 42, Yekaterinburg, Russia

\begin{abstract}
The subject of the article is the theory and practice of sociology food supply in Russia. The purpose of the study is defined as the analysis of the main trends and problems of theory and practice of modern nutrition sociology in Russia. The material of the study was the works of domestic and foreign authors in the field of areas of nutrition sociology, as well as the authors ' sociological research on food culture. Based on the analysis of the main approaches to nutrition research Abroad, the authors highlight the main trends in the development of modern nutrition sociology. The authors ' sociological research on food culture allowed us to identify the main problems in this area, analyze changes in culture nutrition events that occurred during the Covid-19 pandemic. Results of the study we have shown the importance of sociological studies of food culture for a comprehensive solutions to the problem of ensuring food security in the context of economic growth the decline caused by the Covid-19 pandemic. Such research is necessary for the development and implementation of comprehensive programs to improve the efficiency of agri-food systems, support for farms and small businesses in rural areas, social and economic support for vulnerable segments of the population.
\end{abstract}

\section{Introduction}

The sociology of nutrition is currently one of the trending areas of agricultural sociology, both abroad and in Russia. Theoretical and practical issues of the sociology of nutrition are of particular relevance today, as the ongoing Covid-19 pandemic has exacerbated the problem of food security in many countries around the world. The quality and culture of nutrition of various social groups act as the most important component of the sociology of nutrition, at the same time they are the criterion for ensuring the food security of the country. We emphasize that in our country, the sociology of nutrition is only being formed, so the conceptual and methodological issues in this area require further study, and specific sociological studies are waiting for their authors.

Under the sociology of nutrition, we understand a special sociological theory, which is an integral part of modern agricultural sociology. As a special sociological theory, the sociology of nutrition has its own subject and relevant methods for collecting primary sociological information. Its subject field is nutrition as a socio-cultural phenomenon and historically established practice aimed at production, integrated marketing communications,

\footnotetext{
* Corresponding author: alexeyruchkin87@gmail.com
} 
logistics, rituals and everyday actions of people in choosing, preparing, consuming food and disposing of food waste. The core of the subject of the sociology of nutrition is the socio-economic relations in the field of production, distribution and consumption of food, culture and behavior of people in the field of food consumption.

The purpose of our research is to analyze the main trends and problems of the theory and practice of modern nutrition sociology in Russia.

\section{Method}

The material of the study was the works of domestic and foreign authors in the field of nutrition sociology, as well as a sociological study on food culture conducted by the authors. The methods used are divided into two groups. The group of theoretical methods includes: a systematic approach, an analysis of the works of foreign and domestic researchers on the sociology of nutrition, a comparative-historical method. The group of empirical methods includes quantitative and qualitative methods of the sociological study on food culture conducted by the authors in September 2020. The authors used qualitative methods of sociological research, such as narrative interviews, included observation, focus groups, and written surveys (researchers provoked essays on nutrition problems, presented by respondents in free form). Quantitative methods of sociological research were presented by a pilot smart survey $(\mathrm{N}=75)$. The selection of respondents was carried out by the method of "snowball" (snow-ball), based on the fact that representatives of the target group (usually authoritative and well-known members), selected by the researchers, then forward the questionnaire to their network environment, which are included in this group, and they in turn forward to friends and acquaintances. With the help of this method, a sufficiently high motivation for participation and a good quality of filling out the questionnaire were provided, as well as a high speed of conducting the survey was achieved.

The object of the study was the population stratified by age and economic characteristics: young people (up to 32 years old, economically dependent on adult support, striving for economic autonomy), the adult population (from 33 to 60 years old, economically active population) and representatives of "late maturity" (in the terminology of Eric Erickson) from 60 years old, gradually reducing economic activity.

The subject of the study is the reflection of individual food practices.

Among the respondents, $73 \%$ of the respondents were women-traditionally responsible for food and grocery shopping in most family groups, considered by us as an expert audience within the target groups, and $27 \%$ were men. The vast majority of respondents $(95.9 \%)$ are residents of the Russian Federation, and $4.1 \%$ of those who answered the questionnaire have the citizenship of Germany and Ukraine. The age distribution is represented by approximately equal percentage groups-youth and adults (Figure 1). 


\section{Distribution of respondents by age group}

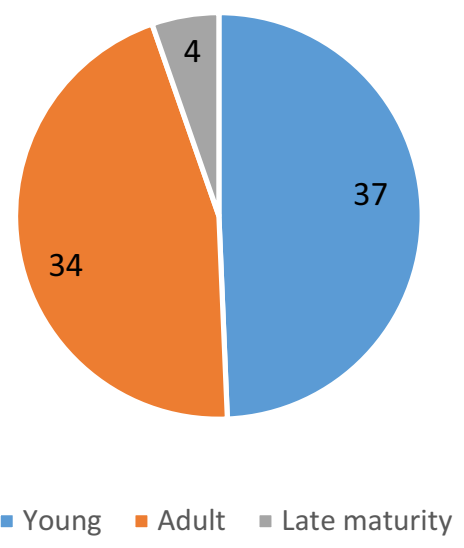

Fig. 1. Distribution of respondents by age group, $\%$

By occupation, the respondents were distributed as follows: $52 \%$ are employed; $39 \%$ are students, students; $7 \%$ are entrepreneurs; $2 \%$ are non-working pensioners and persons engaged in household work and child care. Comparing with the data on income per family member per month, we can conclude that more than half of the families $(53 \%)$ belong to the middle class.

\section{Study detail and result}

Nutrition as a socio-cultural and economic phenomenon became the object of close scientific study in the middle of the last century. At the same time, international organizations began to appear, exploring the ethnographic, medical, and organizational aspects of this global phenomenon. In particular, the institutionalization of this research area was facilitated by the creation in 1945 at the United Nations (UN) of a specialized intergovernmental organization on agriculture-Food and Agriculture Organization (FAO), which raised the problem of food security and unequal access of various social groups to quality food due to economic reasons.

Research in the field of modern sociology of nutrition in foreign sociology is carried out within the framework of the main metaparadigms: classical (Simmel, Sorokin, Marx, Weber), non-classical (Parsons, Goffman, Garfinkel, Homans, etc.) and post-non-classical (Bourdieu, Giddens, Ritzer, etc.).

The classical metaparadigma in the study of the sociology of nutrition, nutrition for the first time begins to be studied as a socio-cultural phenomenon. Nutrition in the interpretation of G. Simmel is an element of culture and a normatively regulated action in society, which prescribes to people what to consume, how regularly and in what social environment. According to Simmel, the etiquette and aesthetics of the meal are of great importance. Food culture, in this way, is a socializing process and a marker of a person's social status [1].

The analysis of the social function of nutrition and the impact of the effects of mass starvation on social destabilization was undertaken by P. A. Sorkin in the work "Hunger as a factor. The influence of hunger on human behavior, social organization, and social life" (1922). P. A. Sorokin considered the main social function of nutrition to be the function of 
social reproduction and social order, and interpreted food shortage as a factor provoking deviant and delinquent behavior (primarily, crime and social protests). In the article "The Sociology of the Revolution", Pitirim Alexandrovich continued his research on this problem, concluding that the causes of the revolution are the result of "infringement of the basic instincts of many people" [2].

Within the framework of the non-classical paradigm of the sociology of nutrition, the developments of the classical paradigm have received their logical development and enrichment. Thus, in the structural and functional analysis, there is an interpretation of nutrition as a social institution with the functions of reproducing social norms and rules for the performance of social roles, for violation of which sanctions follow. T. Parsons presented human action as a self-organizing system based on symbolism and normativity, showing the dependence of individual action on generally accepted values, norms and role expectations [3]. Note that the institutional approach has become one of the leading approaches to the sociological analysis of nutrition.

The merit of the representatives of the phenomenological paradigm (G. Garfinkel, A. Schutz, P. Berger, T. Lukman) we consider drawing attention to the study of routine practices based on the analysis of the processes of inter-individual communication. The emphasis of the phenomenological analysis was placed on the study of the social world in its human dimension in relation to the goals, values and motives of practically active social individuals at the everyday level. These ideas can be applied to the analysis of nutrition and consider it as an intersubjective process of spiritual mutual influence of individuals involved in a joint meal (food practice) [4, p. 530].

The exchange paradigm, represented by its creator, the American sociologist George Homans, explained food practices by the peculiarities of people's social relations at the micro level. Using the deductive-nomological model of analysis, Homans formulated six universal patterns of human behavior depending on the values of "rewards" and "punishments" [5]. Food in the context of this paradigm is considered as a social exchange of rewards and benefits that shape gastronomic tastes, fashion and rituals.

In the post-non-classical paradigm of the sociology of nutrition at the end of the twentieth century, methodological approaches to the study of nutrition as the basis of social health of society and stratification criteria in a postmodern society were proposed. Especially significant were the ideas expressed in the work of the French sociologist Pierre Bourdieu "Discrimination: a social critique of judgment", which we consider to be an important theoretical and methodological basis for the modern sociology of nutrition. According to the scientist, a crucial role in the organization of routine nutrition practices is played by the habitus of the group to which a person belongs.

Habitus in the interpretation of P. Bourdieu acts as a structured attitude and a system of stable collective and individual attitudes that form a matrix of perception, thinking and behavior of people as representatives of social groups that occupy the same positions in the social field. He considers habitus "the generative principle of objectively classified practices and at the same time the system of classification of these practices" that form the space of life styles [6, p. 537].

According to P. Bourdieu, it is the habits, not the financial situation, that influence the socio-cultural rules and internalized norms, including food practices and gastronomic preferences, acting as an integrative characteristic of the lifestyle and "practical operators" that transform the consumed items into signs of social differences. Thus, nutrition practices become markers of different social positions along with other resources that allow us to maintain a similar system of intentions that characterize a certain lifestyle.

The idea of a lifestyle as a set of capitals and distinctive patterns of behavior, later served as an explanatory model for studying the theoretical and empirical features of routine food practices, contributing to the development of the sociology of nutrition. As an 
example of such studies, we will cite the works that we relied on in our study: Kaplan P. ("Food, Health and Identity", London, 1997) [7], Fischler K. ("Food habits, social change and the dilemma of nature / culture", 1980) [8], George Ritzer ("Macdonaldization of society 5", 2011), [9], Spurlock M. Fast Food and Fattening America, 2005) [10], Mayfield, L. E., Bennett, R. M., Tranter, R. B., and Wooldridge, M. J. ("Consumption of environmentally friendly foods in the United Kingdom, Italy, and Sweden and how it may be affected by consumer attitudes to animal welfare and behavior", 2007) [11], Kyahari, A. ("Long-term changes in healthy food consumption in Finland in 1985-2016: an age-period cohort analysis, 2021) [12], et al. Currently, research on the sociology of nutrition is one of the trends of modern sociology abroad.

In Russia, there are two centers for the study of the phenomenon of nutrition - Moscow and St. Petersburg.

Representatives of the Moscow School, led by Professor S. A. Kravchenko (D. N. Karpova, A.V. Noskova, etc.), study the problems of nutrition as a marker of economic inequality in modern society [13]. Representatives of this school consider such phenomena as fast food (J. Ritzer), the Italian Slow Food movement, freeganism, dumpster diving and a number of other relevant global modern problems.

Representatives of the St. Petersburg school Veselov Yu. V., Minina V. N., G. I. Semenova and others pay special attention to the analysis of modern public catering practices. In the works of representatives of this school, the connection of nutrition with the social stratification of society, economic and cultural inequality of representatives of different strata is emphasized [13, p. 37].

The analysis of foreign and domestic literature on the theoretical issues of the sociology of nutrition allowed us to draw the following conclusions. Today, the sociology of nutrition has developed as a special sociological theory that studies nutrition as a socio-cultural phenomenon. Nutrition as a socio-cultural phenomenon performs the function of reproducing human capital and preserving the physical, psychological and social health of the population. The sociology of nutrition is an integral part of agricultural sociology, but retains its subject and relevant methods of collecting primary sociological information. This position of the sociology of nutrition allows us to analyze the relationship between nutrition and agricultural production and makes it possible to predict the qualitative and quantitative characteristics of food as its final result.

Its subject field is nutrition as a socio-cultural phenomenon, a social process and a historically established system of social relations aimed at production, integrated marketing communications, logistics, rituals and everyday actions of people in choosing, preparing, consuming food and disposing of food waste, as well as stratification, ethno-cultural, age and gender differences that affect routine food practices.

The core of the subject of the sociology of nutrition, therefore, is the interaction of social communities involved in the system of production, distribution and consumption of food in a particular socio-cultural space. The needs, interests, attitudes, values, and behavioral motivations of food producers, intermediaries, sellers, and consumers may diverge, creating conflicting relationships and problems that make it possible to build a state food security policy by studying them. In other words, the subject core of the sociology of nutrition is the culture of nutrition. We consider food culture as food practices that have developed in certain social groups, including the production, distribution and consumption of food, traditions, moral norms and etiquette rules associated with eating, as well as the degree of awareness of such practices.

The analysis of the theory of agrarian sociology allows us to identify the main trends in this area. The first trend is the active development of nutrition sociology as a branch of agricultural sociology and its transformation into a relatively independent branch of sociology. Today, despite its close connection with agricultural sociology, the sociology of 
nutrition expands its functions, structure, and subject field, entering new research problems that require new approaches and relevant methods for collecting empirical information. The enrichment of the theory and the arsenal of empirical methods, high publication and scientific-organizational activity (symposia, conferences, round tables, scientific seminars) trigger the processes of differentiation and subsequent "spin-off" of the sociology of nutrition from the "parent" discipline, and obtaining the status of a separate independent branch of sociological science.

The second trend is the formation of openness and interdisciplinarity of the sociology of nutrition, which creates a synergistic effect of mutual enrichment of the use of scientific resources not only with agricultural sociology, but also with most other branch of sociological sciences, with general sociological theory, humanities and natural science knowledge (for example, biosociology).

We are primarily talking about general problematic phenomena and highlighting the trending and most promising areas in sociology, such as: new reality, changing technological structures, challenges of the digital economy and artificial intelligence, globalization and deglobalization, culture and education, greening of sociality, transition to a circular economy, the effectiveness of social reform, social stratification, social inequality, social health, preservation and development of human capital, urbanization and deurbanization, the role of women in the family and society, consumer preferences of various social groups, new social movements, and many others.

These research problems allow us to understand the phenomenon of nutrition in the frame of contradictory processes and changes in the social space of modern society. The description and analysis of nutrition as a social institution and cultural phenomenon will help to identify problems and trends in the development of social processes that affect production, marketing communications, logistics, food culture, food preferences, and the organization of both public and domestic food consumption.

In the sociology of nutrition, there is a process of forming a categorical apparatus and fundamental definitions.

Nutrition is considered in this special sociological theory from various points of view: as an identification and / or ideological factor, a value, a stratification marker, a normative prescription, a basis for the reproduction of human capital, a characteristic of the existence of various social communities and established ways of life [14, p.11].

Together with other sociological disciplines, and primarily agricultural sociology, the sociology of nutrition examines the problems of the availability and quality of food, the culture of food consumption, and the factors of the social and natural environment on which people's health depends. We can say that nutrition is studied comprehensively at the theoretical and applied levels, taking into account the state policy and the efforts of the person himself to choose a model of a healthy lifestyle.

An important role in the development of the sociology of nutrition is played by obtaining factor-fixing knowledge and working out relevant methods for collecting specific sociological information in the study of nutrition and gastronomic behavior of people. We consider it appropriate for the further development of the sociology of nutrition to provide a reflexive analysis of the empirical methods used by us and to assess their relevance.

The experience of our research allows us to conclude about the effectiveness of integrated approaches in the study of nutrition as a daily practice, including qualitative and quantitative strategies $[15 ; 16$, p. 107]. We used quantitative methods in the form of a questionnaire survey in two versions: a handout questionnaire and a smart survey, which allowed us to quantify and typologize factual data, identifying typical groups of eating behavior and their quantitative characteristics. Qualitative methods (focus groups, reflexive essays provoked by researchers, narrative and expert interviews) allowed us to carry out a semantic interpretation of the data, to clarify the attitudes and motivation of the respondents 
' eating behavior as representatives of the target groups. Such a combination of strategies, in our opinion, is optimal for obtaining reliable results, and the applied research methods allowed us to conclude that their goal-achievement is sufficiently high to solve the cognitive problems of the sociology of nutrition.

Analysis of the results of the study allowed us to conclude that the majority of respondents have a fairly conscious attitude to their diet. $86 \%$ of the respondents rated their food culture, mostly good and satisfactory (Figure 2).

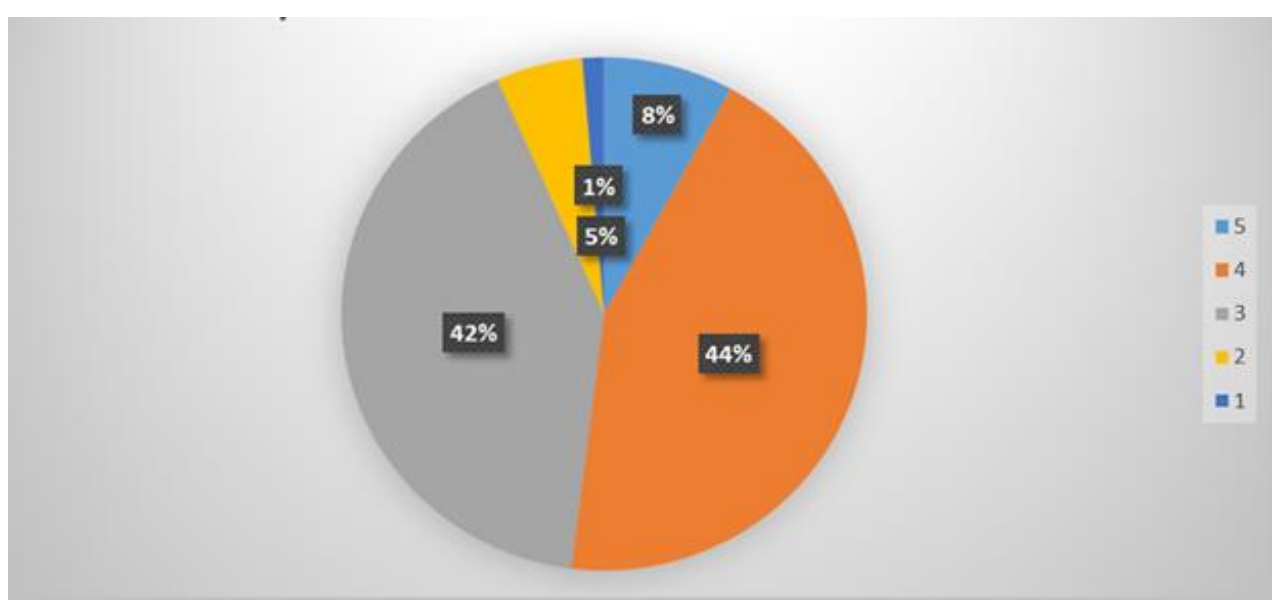

Fig. 2. Nutrition assessment based on a 5 -point system $8 \%$ of respondents rate their food practices as excellent, and only $6 \%$ - as unsatisfactory.

When asked whether the respondents adhere to the principles of healthy eating, $73 \%$ of respondents answered positively (Table 1.).

Table 1. The basic principles of a healthy diet, observed by the respondents (percentage of respondents)*

\begin{tabular}{|l|c|c|}
\hline \multicolumn{1}{|c|}{ Principles } & $\begin{array}{c}\text { The rank of } \\
\text { the array }\end{array}$ & $\%$ \\
\hline A varied diet & 1 & 67,8 \\
\hline $\begin{array}{l}\text { Reduce consumption (or minimize } \\
\text { consumption) of harmful products } \\
\text { (mayonnaise, ketchup, "fast food", alcohol, } \\
\text { etc.) Do }\end{array}$ & $2-3$ & 64,4 \\
\hline Not overeat & $2-3$ & 64,4 \\
\hline Eat more fiber - fresh fruits and vegetables & 4 & 61,0 \\
\hline $\begin{array}{l}\text { Drink a sufficient amount (at least 2 liters } \\
\text { per day) of non-carbonated drinking water }\end{array}$ & 5 & 59,3 \\
\hline There is a sitting & 6 & 57,6 \\
\hline Eat freshly prepared food & 7 & 47,5 \\
\hline Actively move throughout the day & 9 & 55,2 \\
\hline Eat mostly natural organic food & 10 & 45,8 \\
\hline Slow eating (careful chewing of food) & 90,7 \\
\hline
\end{tabular}

Source: compiled by the authors. The sum of percentages exceeds 100, as respondents noted several.

When answering the question about the regularity of daily meals, the majority of respondents showed a tendency to traditional three meals a day $42.7 \%$ and fractional meals $38.7 \%$, the other answers are not statistically significant. $67 \%$ of respondents take care of their health by regularly taking vitamins and useful dietary supplements. 
However, the results obtained by us demonstrate contradictory practices of the respondents ' eating behavior. So for snacks between main meals, along with healthy foodsfruits, water, fermented milk products, $32 \%$ of respondents use sweets, caffeinated drinks, fast food, unnatural products and "food garbage" (Figure 3).

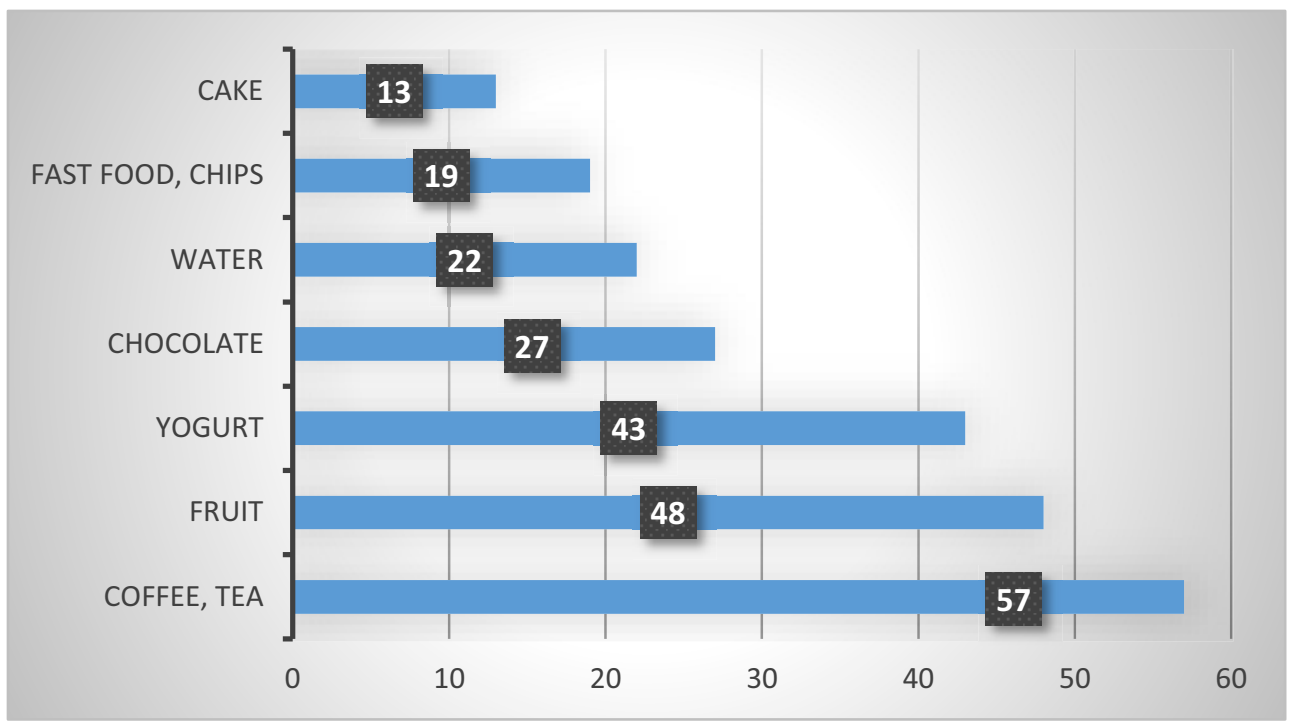

Fig. 3. Foods selected by respondents for snacking.

The presence of problems in the organization of healthy eating among some respondents is also confirmed by the analysis of the personal documents of the study participants - their essay on food culture, which was asked to write in the form of detailed answers to questions. The respondents gave their preference to home food, but noted that " it is not always possible to eat at home, often you have to eat anything because of the busy work and study schedule." At the same time, many respondents write about their desire for a healthy diet, about restrictions in the use of fast food, about finding products that would optimally combine price and quality, as well as about making a daily diet that would "contain the necessary amount of proteins, fats, carbohydrates, vitamins and trace elements."

Today, many scientists are trying to understand and explain how the Covid-19 pandemic and the resulting isolation regime, periodic lockdowns, and economic crisis have affected people's food culture. The main question of the study was whether the diet of the respondents changed during the Covid-19 pandemic.

The majority of respondents $(62.7 \%)$ did not notice any special differences in nutrition. At the same time, retail data shows a massive shift of consumers to online shopping and grocery delivery services. Customers began to pay more attention to the quality of products. According to VTSIOM, during the pandemic, every third Russian (34\%) was willing to overpay for a product if it was marked with the state label of an organic product, and the product itself was produced without the use of pesticides, GMOs and plant growth stimulants [17]. In addition, during the period of self-isolation, the possibility of regular and fractional meals at home appeared, which was noted by the respondents when answering questions about the eating regime.

More than a third $(37.3 \%)$ of respondents saw changes in their diet during the pandemic, and the majority of respondents $(73.3 \%)$ rated them as positive (Table 2 ). 
Table 2. Positive changes in the diet of respondents (percentage of respondents)*

\begin{tabular}{|l|c|c|}
\hline \multicolumn{1}{|c|}{ Principles } & $\begin{array}{c}\text { The rank of } \\
\text { the array }\end{array}$ & $\%$ \\
\hline Less began to eat out of the house & 1 & 61,5 \\
\hline $\begin{array}{l}\text { More often they began to cook their } \\
\text { favorite dishes at home }\end{array}$ & 2 & 53,8 \\
\hline They began to eat more regularly & 3 & 38,5 \\
\hline $\begin{array}{l}\text { They began to pay attention to the } \\
\text { composition and quality of products }\end{array}$ & $4-5$ & 34,6 \\
\hline They began to eat more diverse food & $4-5$ & 34,6 \\
\hline $\begin{array}{l}\text { They began to pay attention to the caloric } \\
\text { content of products }\end{array}$ & 6 & 26,9 \\
\hline $\begin{array}{l}\text { They began to pay more attention to the } \\
\text { food culture }\end{array}$ & 7 & 15,4 \\
\hline $\begin{array}{l}\text { Reoriented to environmentally friendly } \\
\text { products }\end{array}$ & 8 & 11,5 \\
\hline
\end{tabular}

Source: compiled by the authors. The sum of percentages exceeds 100, as respondents noted several.

Among the negative consequences, respondents noted: an increase in food costs in the family budget (40.7\%), weight gain (33.3\%), an uneven diet, frequent snacks $(29.6 \%)$, more frequent purchases of semi-finished products, fast food orders $(22.2 \%)$, more monotonous food $(22.2 \%)$. Despite the presence of some negative changes in the diet of the respondents, the formation of a healthy eating model is evident in the majority of respondents.

We concluded that one of the lessons of the "coronacrisis" was the understanding of the value of health as the backbone of individual human capital. Most of the respondents realized the importance of their own efforts to maintain good health and the role of nutrition in maintaining people's immunity and health.

The results of the study confirmed our hypothesis about the different patterns of eating behavior of the respondents according to the dominant stereotypes and established eating habits.

The first group, which can be conditionally called the youth model, is represented by unstable food practices, orientation to fast food restaurants as convenient and comfortable, places to communicate with friends, fairly regular consumption of fast food and "food garbage", eating on the go, using semi-finished products. This group is characterized by contradictory patterns regarding the use of healthy food; gaps in values and routine food practices. The second group includes respondents with a rational model of nutrition, based on the principles of healthy eating and minimizing the use of "harmful" products for health. Representatives of this group, not being fans of healthy food or permanent diets, prefer home-made breakfasts, lunches and dinners with the family, love and know how to cook, have experience in choosing environmentally friendly products. For them, both ceremonial and aesthetics are important, as well as the quality and benefits of food, a combination of hedonism and the social effect of eating together. The second model we called "ecological", based on our previous research.

Of course, there is a group of "fickle", reacting to fashion, network influence, combining behaviors of the first two models, prone to shying away from overeating to dieting and fasting, irregular eating, food experimentation.

These models do not depend on age and are found in each of the socio-demographic groups. Our future plans include a more detailed study of the patterns of eating behavior of different age cohorts, finding out how the social environment, fashion and mass communication media affect the habits and food preferences of respondents, and, of course, designing recommendations for the formation of a food culture in each of the groups. 


\section{Discussion}

The results of the study revealed a certain re-evaluation of values in the respondents ' food culture that occurred during the Covid-19 pandemic. Nutrition has come to be seen not only as a factor in maintaining immunity and a healthy lifestyle, but also as a way to strengthen family and relationships with other people. A conscious attitude to nutrition as one of the leading values has also made adjustments to everyday food practices. We have diagnosed differences in eating patterns against the background of a trend towards increased investment in nutrition as the basis of human capital. The majority of respondents began to increase spending on high-quality organic food, cook their favorite dishes at home more often, and pay attention to the culture and ritual of the family feast.

The conducted research allowed not only to correct the arsenal of methods of collecting sociological information, but also to expand the methodological foundations of the sociology of nutrition. We emphasize that the study showed the need to study national preferences and problems in the food culture of residents of different countries. We plan to correct the toolkit and translate it into English for the cross-cultural study "Food culture in Russia and India". This will be the next stage in the study of nutrition as a socio-cultural phenomenon that affects the formation of national human capital.

The study showed the importance of sociological studies of food culture for a comprehensive solution to the problem of ensuring food security in the context of the economic downturn caused by the Covid-19 pandemic. Such studies are necessary for the development and implementation of comprehensive programs to improve the efficiency of agri-food systems, support farms and small businesses in rural areas, and social and economic support for vulnerable segments of the population. The problem of food security requires innovative programs for the development of the agro-industrial complex, modernization of the logistics supply chains of food "from the field to the counter", the creation of large wholesale distribution centers and investment in agricultural science, including the sociology of nutrition.

\section{References}

1. G. Simmel, Sotsiologiya: teoriya, metody, marketing, 4, 187-192 (2010) (In Russ.)

2. P.A. Sorokin, Hunger as a factor, The impact of hunger on human behavior, social organization, and social life. Introductory article, compilation, comments (Moscow, Academia \& LVS, XII, 684, 2003) (In Russ.)

3. T. Parsons, On the structure of social action (Moscow: Academic Project, 435, 2018) (In Russ.)

4. V.I. Dobrenkov, American Sociological Thought (Moscow, Edition of the International University of Business and Management, 560, 1996) (In Russ.)

5. J. Homans, Social behavior as an exchange. Modern foreign social psychology (Moscow, Moscow University Press, 82-91, 1984) (In Russ.)

6. P. Bourdieu, Distinction: social criticism of judgment, translated from the French by O. I. Kirchik, Western Economic Sociology: A Textbook of Modern Classics (Moscow: Rossiyskaya politicheskaya enciklopediya (ROSSPEN), 680, 2004) (In Russ.)

7. P. Caplan, Food, Health and Identity (London, Routledge 1997)

8. C. Fischler, Culture Dilemma, Social Science Information, 19(6), 937-953 (1980)

9. J. Ritzer, Macdonaldization of society (Moscow, Praxis Publishing and Consulting Group, 592, 2011) (In Russ.) 
10. M. Spurlock, Don't eat this book! Fast food and fattening America (St. Petersburg, Amphora, 460, 2005) (In Russ.)

11. L.E. Mayfield, R.M. Bennett, R.B. Tranter, M.J. Wooldridge, International Journal of Sociology of Food and Agriculture, 15(3), 59-73 (2007)

12. A. Kähäri, The International Journal of Sociology of Agriculture and Food, 26(2) (2021) DOI:https://doi.org/10.48416/ijsaf.v26i2.55

13. S.A. Kravchenko, Sociocultural dynamics of food: risks, vulnerabilities, demand for humanistic biopolitics (Moscow, MGIMO-University, 198, 2014) (In Russ.)

14. Yu.V. Veselov, Sociological research, 1, 95-104 (2015) (In Russ.)

15. L.A. Zhuravleva, E.V. Zarubina, A.V. Ruchkin, Agrarian Bulletin of the Urals, 10-18 (2020) DOI: 10.32417/1997-4868-2021-13-10-18 (In Russ.)

16. L.A. Zhuravleva, E.V. Zarubina, A.V. Ruchkin, Food culture of student youth as an innovative social group, Agroindustrial complex: strategy of development, Materials of the International scientific and Practical conference "From inertia to development: scientific and innovative support of agriculture", dedicated to the 80th anniversary of the Ural State Agrarian University, Yekaterinburg, 106-112 (2020) (In Russ.)

17. Press release of VTSIOM from 09.06.2020 "Health - the highest value", URL: https://wciom.ru/index.php?id=236\&uid=10321 (2020) (In Russ.) 